\title{
Influence of Ecological Marketing on Society: Emerging Challenges \& Opportunities
}

\author{
Krishan veer Singh \\ Assistant Professor \\ GLA University, Mathura, Uttar Pradesh, India \\ Email: krishanveer.singh@gla.ac.in, mob-919760223795
}

\begin{abstract}
This Article capability in imitation of consigning facts about the impact of inexperienced promoting about class then theirs shopping for conduct. There is a bit explanation in the back of ecological mindfulness; Ecological object includes, Ecological development workout routines and Ecological worth influence charge buying administration of the customers into assured manner. Ecological transformation, practicing environmental awareness, ecological assurance, realistic access over life, thrifty turn regarding events, ensuring our floor yet a bunch extra has grown to be an attribute surprise into our everyday age according to day existence. Ecological Marketing in any other case known as organic showcasing then natural advertising and marketing have come to be an imperative concern of the current quickest rising world. Makers atop the ball are confused upstairs the declining government over the condition or as a result proclaiming the rate over rigid improvement about the economy. In a simple or genuine manner, Ecological marketing does stand characterized namely the showcasing on objects to that amount are dared in conformity with remain naturally sheltered or ground benevolent. This demand bill endeavors after discovering the most perfect ramifications yet significance regarding Ecological promoting. With the end result on that paper, the promoting wish arrives greater secure and the buyers desire to have a safe or situation amicable ingress according to the items. The aftereffect over that resolution delivery note intention help within limiting the wastages then construction circumstance slick, taintless yet safe.
\end{abstract}

Keywords:Ecological Marketing, Opportunities, Challenges, Ecological, Eco-Friendly Practice.

\section{Introduction}

Advancement about inexperienced promoting: The inexperienced showcasing has raised over half an embroider on time. As indicated by Peattie (2001), the development of Ecological promotion has ternary stages. 


\section{First flooring}

The first board was named as "biological" Ecological promoting, and at some stage in it, entire showcasing workouts were involved in conformity with assist situation troubles yet assign solutions because of ecological issues.

\section{Second tribune}

In the posterior platform was "ecological" Ecological advertising or the strength developed of luminous innovation as protected planning regarding creative new items, will deal with contamination yet violate issues.

\section{Third stage}

The stage used to be "reasonable" Ecological promoting. It came between in imitation of conspicuousness among the final portion regarding the 1990s a mid-2000.Albeit natural issues influence each and every alone human action, scarcely someone scholastic controls have included inexperienced issues within their writing. This is particularly legitimate because of advertising. As the community turns out after be extra concerned in relation to the ordinary habitat, businesses bear started in accordance with trade their leading trying in imitation of tackle society's "new" concerns. A little agency holds rushed in imitation of well-known ideas kind of ecological administration frameworks then misuse minimization, and bear coordinated herbal problems within every odd hierarchical movement. Some tightly closed over it is the development over diaries, because of example, "Business Strategy than the Environment" then "Ecological er Management International," which are apparently meant in imitation of thoroughness experiment figuring out together with business' ecological conduct.

One commercial enterprise area where ecological problems have gotten a brush concerning the conversation of the nicely-known and expert press is advertising. Terms like "Ecological Marketing" or "Ecological Marketing" show usually of the famous press. Numerous administrations around the handball bear gotten then worried respecting inexperienced showcasing workouts that they bear endeavored according to direct them (Polonsky 1994a). For instance, in the United States (US) the Federal Trade Commission then the National Association over Attorneys-General bear created large reviews inspecting Ecological marketing issues [FTC 1991, NAAG 1990]. Perhaps the near regarding difficulty together with the inexperienced promoting territory is so at that place has been tiny recreation in conformity with scholastically analyze herbal then Ecological advertising. While partial literature exists [Carlson, Grove, or Kangun 1993, Davis 1992, Davis 1993], such originates beyond unique viewpoints.

\section{What is Ecological Marketing?}

Tragically, a greater portion of men and women accept so inexperiencedly showcasing alludes completely in accordance with the advancement or publicizing concerning gadgets together with natural qualities. Terms as Phosphate Free, Recyclable, Refillable, Ozone Friendly, and Environmentally Friendly are a section on the thing's shoppers many times accomplice with 
inexperienced promoting. While these phrases are Ecological advertising claims, as like a regimen inexperienced showcasing is a lot greater enormous idea, one as may be applied in conformity with customer merchandise, present-day products yet to administrations. For instance, the ball over so are resorting up to expectation are beginning in accordance with increase themselves namely "ecotourist" offices, i.e., places of work so "practice" between encountering characteristic of pursuit between a manner to that amount limits their ecological effect [May 1991, Ingram then Durst 1989, Troumbis 1991].

Subsequently, Ecological showcasing fuses a large scope about exercises, which includes item alteration, modifications after the introduction cycle, bundling changes, simply so adjusting publicizing. However, characterizing Ecological showcasing is truly now not a simple undertaking. Undoubtedly the phrasing utilized around even has differed, it incorporates Ecological Marketing, Environmental Marketing, and Ecological Marketing. While inexperienced advertising became a force in imitation of lie reckoned with within the remaining portion concerning the 1980s yet mid-1990s, that was forward examined a bunch before. The United States of America Marketing Association (AMA) held the essential manufactory over "Biological Marketing" in 1975. The techniques concerning its event delivered touching certain concerning the predominant books about inexperienced advertising named "Environmental Marketing" [Henion and Kinnear 1976a]. Since so much era a number of distinct books concerning the subject have been disbursed [Charter 1992, Coddington 1993, Ottman 1993].

The AMA factory endeavored after put to scholastics, experts, then public approach producers in conformity with inspect showcasing's impact concerning the indigenous habitat. At this event, herbal marketing was once characterized as: "The care on the high quality and negative components regarding promotion workouts regarding contamination, power slander yet no vigor commodity consumption." [Henion and Kinnear 1976] This short appointment has 3 answer segments,

1. It is a subset of the universal advertising action;

2. It analyzes both the fantastic or poor exercises; then

3. A slight scope on ecological problems is inspected.

While its setting is a beneficial opening stage, after stand far-reaching Ecological showcasing should lie entirely the extra extensively characterized. Before award, a non-obligatory definition, such labor according to stay observed as no person appointment and phrasing has been commonly acknowledged. This non-appearance concerning consistency is a substantial taxpayer in imitation of the issue because by using where approach can trouble is assessed if entire scientists bear an exchange impact on as she is exploring. The accompanying setting is a brush more extensive than these on special scientists yet it envelops all giant parts about specific definitions. My setting is: "Ecological and Environmental Marketing includes about whole workout routines intended in accordance with gender or encourage anybody trades anticipated 
after redacting human wishes and needs, in accordance with certain a volume that the success on this requirement or needs happens, along with poor negative effect concerning the indigenous habitat." [Polonsky 1994b,

This joins a significant share on the long-established segments of the advertising and marketing rating as is "All exercises meant in imitation of origin and motivate somebody trades planned in imitation of accomplishing human desires or needs" [Stanton or Futrell 1987]. Thusly such guarantees that the hobbies on the association then every one of its purchasers is ensured, as deliberate trade won't appear barring salvo each the client yet supplier frequently advantage. The atop rating moreover comprises the vow about the common habitat, with the aid of careful to the government the unfavorable impact this career has concerning the earth. This following point is significant because human utilization by using its extraordinary nature is risky in conformity with the common habitat. (To be unique gadgets working Ecological instances have to the regimen he is "less naturally hurtful" as opposed in conformity with toughness "Ecologically Friendly.") ThusEcological advertising and marketing have to receive a gander at limiting natural damage, no longer certainly disposing of it.

\section{Literature review}

Cateora Graham, between International Marketing, has continuously an amount rank into inexperienced advertising yet object advancement. The Inventor has referred to an assortment about fashions the place the importance regarding Ecological showcasing has been laid spotlight on. Ecological advertising is a term old according to differentiate fear including the natural results concerning an assortment of showcasing exercises. It is evident beside the creator's resolution or models the bundling or intensive misuse ideas are tough but even are fecund situations regarding fulfilling regional recommendations namely well namely forlorn the option after movement it road in conformity with treatment along with distinct business sectors.

Philip Kotler or Kevin Lane Keller of Marketing Management has started the point with the aid of inspecting about the value over Ecological showcasing among the preceding just some many years or has moreover talked regarding the explosion over ecologically inviting items. Nonetheless, namely indicated by using the Inventor beside the description viewpoint Ecological promoting applications have not been effective. Advertisers tried then fizzled with inexperienced tries after sealing the treat between the course concerning the almost recent decennary in light over particular hindrances who the improvement experienced. The client leading is together with the end aim so much near consumers show on reluctantly after the surrender the blessings regarding exceptional alternatives after select Ecological items. Alongside definitions beside more than a few sources.

Debraj Dutta then Mahua Dutta, of Marketing Management, bear addicted a clarification about such as is Ecological promoting. As per the creators, inexperienced advertising and marketing join a large scope regarding workout routines along with the consistency of an item, advent ring 
yet bundling. The creators hold either talked as regards an associate of composition sources as hold zeroed into on inexperienced promotion and its fitness into the present period. It was apparently so much the dynamic motives into digest concerning which associations participate between inexperienced promoting.

K.K. Shrivastava and Sujata Khandai, the creator of Consumer Behavior in Indian Context, has talked respecting Ecological showcasing act of kinship together with the global enterprises. These surface a developing assortment regarding regulations meant by address natural issues. Worldwide worry because of makeup stretches abroad past mechanical contamination, unstable garbage elimination or considerable deforestation according to contain problems up to expectation power legitimately over consumer items.

\section{Objective about the study}

- To individualize the purchasers to satisfy their needs.

- To perform mindfulness regarding the Ecological cycle, Environmental, Sustainable, Ecological Marketing measure.

- To teach the purchasers as regards Ecological Marketing.

- To discover the methods after makes use of the greatest property within a practicable way. - To discover the tremendous difficulties to that amount inexperienced showcasing is likely current after confront.

\section{Research methodology}

Secondary Data: During my Research I have utilized the non-obligatory information strategy so beneath:

a) It is received beyond current writing, more than a few researchers' then analysts' dispensed books, articles disbursed between a variety of diaries, periodicals, gathering paper, deed paper, magazines, newspaper, centric yet regime site.

b) The non-obligatory statistics yet statistics will damage under because putting up the order widely.

\section{Results or discussion}

The administration, legislators, or penurity about biz concerning laws have been re-ported namely elements favorable for a huge quantity on the herbal issues. Respondents, into addition, sense so even is tiny that humans execute whole single do in conformity with scale down ecological corruption. It is pretty rule groups then stricter biz concerning laws that execute assist between making sure then assisting the earth. The outcomes are abroad beside after the ineffectual scattering about statistics yet shopper education concerning different ecological issues/issues and enactments. A vile quantity on ecological mindfulness calls because of greater big simply as extensive endeavors along with honor to one of a kind regime then non- 
government associations (NGOs) occupied with showcasing about inexperienced thoughts because of working folks totally mindful or realized on herbal problems than issues.

\section{Findings}

Significant Findings over my examination paper is-

- The test discoveries show to that amount clients bear a consolidated inspirational precept closer to Ecological Marketing.

- These days shoppers are greater conscious over herbal issues.

- Consumers comport by that: "In future, an ever-increasing number over consumers wish incline toward Ecological items."

- Consumers comport in imitation of that: "Organizations as may construct over themselves together with Ecological photograph choice bear unmistakable fortunate position in the commercial center."

\section{Suggestions}

Based on my exploration so are little proposals regarding Ecological showcasing areas care of the following-

\section{Eco-Labeling}

The increasing ecological issues over buyers are provocation extra records about the herbal attributes over items life performed on hand by makers thru such as is precise "eco-naming". Eco-naming has between this way emerge as the middling advancing both the advent or utilization over objects up to expectation is "greater situation neighborly" than contending items handy among the market. Because of this, eco-naming has built significant dialogue as by its pointers because of demand get right of entry to about comparative items and with honor in imitation of the lawfulness of soliciting for ecolabelling of items, specifically into the World Trade Organization (WTO). The composition shortly examines the need of access affects about eco-naming plans, mainly because of creating nations. It talks regarding the propriety of willful lifestyles halo investigation (LCA) based eco-naming, supported each via governments simply namely those with the aid of non-administrative bodies, together with the necessary preparations concerning the WTO Agreement regarding Technical Barriers to Trade (TBT Agreement) and recommendations condition it is viewed so secured via the relevant WTO arrangements, as has been assured with the aid of secure nations.

\section{Ecological racing}

Throughout the lengthy-term, Ecological problems bear been extra discussed via business than industry, budgetary foundations then the ordinary population. There has been a brush over the conversation as regards the floor yet the harming influences are delivered by using normal exercises. Broad ecological damage has been brought about ceaseless utilization, advertising, assembling, dealing with, or dirtying, along with a few herbal catastrophes. There are distinctive 
reactions after Ecological problems to that amount agencies hold received. These thoroughness Ecological item advancement, inexperienced showcasing, ecological administration, or focusing on manageability. This article provides the aftereffects over examination getting to know the Ecological techniques then practices within an example over organizations. It further relates issues, because of example, environmental concerns, upkeep, or company conventional obligation. Natural NGO-business communitarian associations, generally referred to as inexperienced coalitions, are empowering corporate entrepreneurship, pioneering developments up to expectation address ecological troubles and result in operational efficiencies, latter advances, or alluring 'Ecological ' items., ecological.

\section{Conclusions}

Ecological showcasing covers extra concerning an association's merchandising claims. While companies have to bear a substantial share of the constraint involving herbal corruption, in the end, such is purchasers anybody applies products, or because of this make ecological issues. One litigation about it is the vicinity McDonald's is often accused because of dirtying the earth due to the fact a cluster concerning theirs bundling wraps over as much facet regarding the avenue squander. It must keep recalled up to the expectation that is the unfeeling patron whichever decides according to discards their breach in the wrong manner. While corporations perform extensively affect the indigenous habitat, the obligation duty does not remain theirs alone. In the EPA's 1994 experiment consumers gave the accessory explanations in the back of in which way they damage to nature.

Apparently, buyers are not excessively dedicated after improving their circumstance then would possibly stay hoping to load a fascicle about coercion of industry yet government. Eventually, Ecological showcasing necessitates to that amount buyers want a cleaner situation yet are keen to "pay" because it, possibly through extra luxurious merchandise, and altered person approaches concerning life, yet too executive mediation. Until that happens such desire stands solid because of the firm's individual in conformity with the government the inexperienced advertising transformation.

Having pronounced this, such should no longer stand unnoticed that the mechanical client additionally can oblige carriers to barter their exercises. Subsequently, an ecological filed affiliation may not just birth occupation so hold low their destructive impact concerning the earth, that can also eke have the option to force their companies according to lift on into a whole the extra naturally "capable" design. Last consumers or mechanical consumers additionally can constrain associations according to incorporate the soil in their company tradition yet subsequently warranty entire associations power the detrimental ecological effect over their exercises.

\section{Conflicts of interest and financial disclosures: NA}




\section{Reference}

[1] American Marketing Association (Resource Library) (n.d.). Dictionary.

Retrievedfromhttp://www.marketingpower.com/_layouts/dictionary.aspx?dLetter=G.

[2] Chowdhary, S., \& Dasani, L. (2013). Ecological marketing - A new corporate social responsibility. INCON-VIII International Conference on Ongoing Research and IT, Pune, India, January, 11- 13, 2013.

[3] Dey, D. (2007). Energy efficiency initiatives: Indian experience. ICFAI Business School, Kolkata, Retrieved from http://ebookbrowse.com/dey-paper-pdf- d173493648

[4] Government of Andhra Pradesh (2010, June 29). New Industrial Policy of Andhra Pradesh2010-2015. 